CCC 2019

Proceedings of the Creative Construction Conference (2019) 122

Edited by: Miroslaw J. Skibniewski \& Miklos Hajdu

https://doi.org/10.3311/CCC2019-122

Creative Construction Conference 2019, CCC 2019, 29 June - 2 July 2019, Budapest, Hungary

\title{
On-site quality assurance: moving from forms to digital capture
}

\author{
Christian Nordahl Rolfsen ${ }^{\mathrm{a}^{*}}$, Ann Karina Lassen ${ }^{\mathrm{a}}$, \\ Mohamed Mohamed ${ }^{\mathrm{b}}$, Adnan Shakari ${ }^{\mathrm{b}}$, Homayoun Yosefi $^{\mathrm{b}}$ \\ a Oslo Metropolitan University, 0130 Oslo, Norway \\ b previously Oslo and Akershus University College of Applied Sciences
}

\begin{abstract}
The construction industry is in the midst of a transition with traditional design systems being replaced by novel 3D modelling technologies. This transition takes place gradually rather than radically, and while new systems (e.g. Building Information Modelling, BIM) become increasingly diffused in the industry, many legacy systems and practices are left intact. Quality assurance using the old method of filling out forms for the registration of errors and omissions is replaced by systems such as RIB Capture, where an app on a mobile phone is used to take a photo which is immediately sent to the person involved, e. g. carpenter, plumber, electrician etc. We ran a case study in a large industry standard type of residential project executed by a contractor. Data were collected based on a series of qualitative interviews conducted with the on-site personnel. This was analyzed according to the Technology Acceptance Model, which explains how individuals develop an intention to use new technology. Our contribution to the body of literature is that we compare the technology acceptance of new and existing quality assurance methods in order to unearth their relative advantages. This work is important for managers deciding on a combination of quality control tools, enabling them to better run their projects efficiently.
\end{abstract}

(C) 2019 The Authors. Published by Budapest University of Technology and Economics \& Diamond Congress Ltd.

Peer-review under responsibility of the scientific committee of the Creative Construction Conference 2019.

Keywords: RIB Capture, Construction Management, Technology Acceptance Model, Quality assurance.

\section{Introduction}

Quality assurance is, in construction as in other fields, a central goal for all deliverances. Quality can be understood as a condition free of deficiencies [1]. According to several studies, most building defects originate during production or construction [2], and they are costly - accounting for approximately $15 \%$ of the total construction costs [3]. While prevention would be preferable, it is not always possible or even the most cost-effective [4], so there will always be a need for appraisal and correction of failure.

Digitization, headed by Building Information Modelling (BIM), has taken over as the preferred method for anything from design collaboration to scheduling, cost planning, and facility management; improving efficiency and quality along the whole chain [5]. Digital tools are not reserved for designers and consultants at their desks, as on-site workers are also embracing the technology with access to the 3D model on mobile devices. Along with this development, numerous associated mobile apps are made available for the construction phase, offering tools for anything from model viewing and safety monitoring [6] to note taking, invoicing and form filling - the latter going under the label of workflow apps.

*Christian Nordahl Rolfsen: Author email: crolfsen@oslomet.no 
Mobile apps specifically designed for construction defect management, also called snagging apps, are meant to simplify surveys, inspections, reporting, communication, and more, and thus improve the handover process. Instead of filling out and updating detailed paper forms describing the nature, location, responsible person and status of each issue and taking steps to communicate this information to the right persons, snapshots are taken, the position is indicated on a floor plan, and instructions are sent directly to the responsible persons. All is handled on smartphones or tablets [7].

This represents a significant change in work procedures. As with all institutional change, it might happen that the transition is resisted [8]. This might be because the new technology is perceived not to be useful, or found to be difficult to use [9]. It is important for change to happen that the users experience relative advantage of new solutions over the familiar processes that they replace [10].

Wishing to answer the question "Will digital quality management systems be accepted by the parties involved on construction sites?" we conducted a case study and interviews with project managers and on-site workers on various building projects in Norway, where the RIB Capture snagging app [11] was deployed. The interview questions were guided by the Technology Acceptance Model (TAM) [9], our chosen theoretical approach. Thus, we hope to disclose any barriers to the employment of a relatively new technology that might improve the quality of buildings under construction.

This article starts with an introduction to the theoretical lens, next, the software and our research method are described. Findings are presented and analyzed according to the theoretical construct, and finally the discussion and conclusion answer the research question.

\section{Theoretical Lens}

Several theoretical models explaining adoption and acceptance of new technology exist (e.g. Technology Acceptance Model, Unified Theory of Acceptance and Use of Technology, Actor Network Theory, and Diffusion of Innovations) [12]. The technology acceptance model (TAM) has informed research on the user acceptance of building management systems as well as research on individual beliefs about the outcomes of BIM use [13, 14]. TAM can be viewed as an adaptation of the theory of reasoned action (TRA) to the field of information systems [15]. The model depicted in figure 1 builds on the original TAM model introduced by Davis [16] and the theoretical extensions (e.g. TAM2) suggested by Venkatesh and Davis [17]. Diverging from the original TAM and TAM2 models, the construct names 'intention to use' and 'usage behavior' have been replaced with 'behavioral intention to use' and 'actual system use' respectively. This has been done in accordance with what has been proposed by Venkatesh et al.[15]. TAM suggests that perceived usefulness and perceived ease of use will determine an individual's intention to use, and sees 'behavioral intention to use' as a mediator of actual system use. A strong emphasis is placed on the user's subjective opinion.

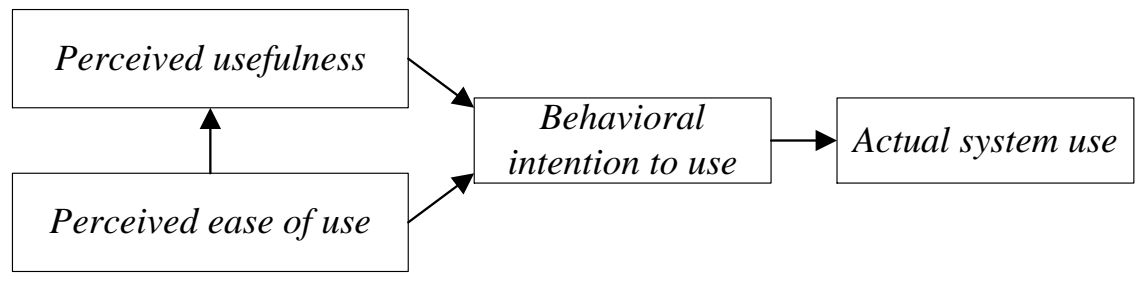

Figure 1.Technology acceptance model $[9,15,16]$

The main TAM constructs are: (1) Perceived usefulness - "the degree to which a person believes that using a particular system would enhance his or her job performance" [ p.320, 18]; (2) Perceived ease of use - "the degree to which a person believes that using a particular system would be free of effort" [ p.320, 18]; (3) Behavioral intention to use - users' intention of use of the system in the future [15]; (4) Actual system use - users' 'real' use of the system for performing work tasks [15]. TAM has proven its value for explaining how users come to accept and use new technology, making it a good fit for our study [19]. 
C. N. Rolfsen, A. K. Lassen, M. Mohamed, A. Shakari, H. Yosefi/ Proceedings of the Creative Construction Conference (2019) 122 https://doi.org/10.3311/CCC2019-122

\section{Method}

A case study was considered appropriate since it allows for exploring "sticky practice based problems where the experience of the actors are important and the context of the action is critical" [p.370, 20]. We decided to conduct our main case study on an apartment building construction project in Oslo, Norway. We started by presenting the defect management application RIB Capture to the team at Contractor \#1. Next, two separate inspections were carried out with RIB Capture on the case site, with a project engineer and a site manager attending. Various functions of the app were explored: registering the project, 2D drawings and involved parties, registering nonconformities, snapping photos and marking their locations in the plans, and linking each issue to the appropriate sub-contractor. We participated in the inspections to get an impression of the users' benefits from using the program and of their practical understanding of the application itself. Interviews were conducted a couple of weeks after the demonstrations, when the users, including sub-contractors, had had a chance to gain some experience with using the system. Our data was collected through semi-structured interviews, using face to face, Skype and email, with nine construction professionals working on various sites, as a way to access the interpretations of informants in the field. The interviews were conducted in October 2016, at a point in time when the design and construction had not been finalized. To supplement the research, we also interviewed professionals w three other contractors. Table 1 provides an overview of the interviews conducted. Interview guides were designed based on the Technology Acceptance Model.

\begin{tabular}{lll} 
Table 1. Interviews conducted. & & \\
\hline Affiliation & Service provided & Interview technique and duration \\
\hline Case project/ Contractor \# 1 & Project Engineer \# 1 & Face-to face, 45 min \\
Case project/ Contractor \# 1 & Site Manager \# 1 & Face-to face, 45 min \\
Case project/ Contractor \# 1 & Project Manager \# 1 & Email \\
Case project/ Contractor \# 1 & Carpenter \# 1 and Plumber \# 1 & Group interview/ Face-to face 40 min \\
Contractor \# 2 & Site Manager \# 2 & Phone interview, 40 min \\
Contractor \# 3 & Site Manager \# 3 & Skype/ telephone, 40 min \\
Contractor \# 3 & Trainee \# 1 & Skype/ webcam, 40 min \\
Contractor \# 4 & Project Manager \# 2 & Email \\
\hline
\end{tabular}

\section{Analysis}

The analysis follows the structure suggested by the Technology Acceptance Model presented in chapter 2. First, the contractors` perceived usefulness of RIB Capture for carrying out their work is presented. Second, the perceived ease of use of the application in the context of on-site construction work is presented. Third, the behavioral intention to continue using RIB Capture for construction works as an indicator for actual system use in other projects is disclosed.

\subsection{Perceived usefulness}

Throughout the interviews, several factors were found influential for construction professionals' perceptions of usefulness. The first candidates we interviewed were site managers and a project engineer. They were convinced that a good flow of communication is important in order to keep a good flow of work. This was enabled through the application's dialogue center, as pointed out by a site manager: 'If, for example, I write that 'you need to fix a skirting board', or window moulding, then he can answer immediately and say that 'that's not my job, it's the carpenter's'. Then I can just change the contractor and send the message again'. He added other ways in which time can be saved: 'It takes less than a minute to note a fault and take a photo and send it to the person concerned. They get it immediately.' Furthermore, he went on to say that "They know what they have to fix, so we can leave the flat and they can go in and do the job, so that we don't have to go through the faults", indicating that the system enabled the subcontractor to accomplish the task without further instructions. (Site manager \#2).

Another site manager further elaborated on this, explaining how productivity and effectiveness on site is increased: "I would say that our craftspersons and subcontractors have taken a positive view because they think it's good that they can go out on the site and don't have to spend time walking back and forth to look through lots of documents and binders. It's very convenient not 
C. N. Rolfsen, A. K. Lassen, M. Mohamed, A. Shakari, H. Yosefi/ Proceedings of the Creative Construction Conference (2019) 122 https://doi.org/10.3311/CCC2019-122

having to deal with paperwork." Furthermore, effectivity in the office is enhanced: "It's useful because you don't have to use documents. That's the thing. You can sort things more easily. You get the whole overview [...] You can sort things by flat, discipline etc." (Site manager \#1).

Contractor \#1 had previously used a general workflow app to register nonconformities. This method in many ways resembles the traditional method of operating with paper forms and physical files. When experiencing the functionalities of RIB Capture, the project engineer interviewed at the main case study commented: "it's easy to communicate with the different parties through the dialogue center, and take photos and have systematic documentation. It's easy compared to the traditional method." (Project engineer \#1).

We were interested in hearing how all actors perceived the new tool in terms of usefulness, including the skilled workers. After all, they are the ones doing the actual work on site. We therefore conducted a brief group interview with the carpenter foreman and plumber foreman at the main case study. They said the following: "It's quicker, easier to keep track of things." (Plumber foreman \#1). "In the past, we got emails with a list of faults and defects, and after we had gone through it, we went to the office to have it signed. In a way, the answer is that with RIB Capture, you don't have to make that trip to the office, and everything is in the same place." (Carpenter foreman \#1).

\subsection{Perceived ease of use}

After having tried the application for a few weeks on site, the users were asked how easy they perceived it to be. On site, some were skeptical at first: 'I was maybe a little skeptical of the application, but it went ok' (Carpenter foreman \#1). However, in just a short time, the users found the application easy to use and that it simplified their work. This is supported by the following quote: "It's very easy to use. As I said to the subcontractors on the construction site: 'get to know the application, play around with it a bit.' And after a few hours they were up on it." (Project engineer \#1, Case project). 'I find it very easy to use [...] If you can use a computer, you can use this." (Site manager \#2).

In general, new digital tools require training of users. Nearly all the respondents found this easy. 'Training doesn't take long. [...]. If the subcontractors ask for help, we in the construction site management help them, but there haven't been any particular difficulties' (Trainee \#1, Case project).

It was found that age can be an obstacle to using digital tools on the construction site, even though the program is not very advanced. When asked whether there were any disadvantages, one project manager who had some experience said: "Those without sufficient smartphone competence struggle" (Project manager \#2), adding: "And there's not much of that these days." This was supported by another: "RIB Capture is a modern tool in an age where mobile phones or tablets are used for most things" (Site manager \#1, Case project).

\subsection{Behavioral intention to use and Actual system use.}

The behavioral intention of using RIB Capture in future construction projects is evident, in spite of some initial skepticism: "Yes, we want to use it for the next block of flats as well. We want to learn more about the software so that we can carry out a good assessment of whether we want to continue using it. [...]. If it's profitable, then we'll certainly give it a go." (Project manager \#1, Case project). His colleague was even more positive: "Word is getting around here that we are using a program that works well, so we have informed the other projects. [...] I would definitely recommend RIB Capture to others. I'll be going down to a project close by shortly where we'll be doing a really big project with 440 flats, and I will definitely mention it (RIB Capture) there" (Project engineer \#1, Case project).

Contractor \#3 have been using RIB Capture for several years, and never looked back. In this respect, one could say that once the decision to take the system into use has been taken, the way forward to actually use it was clear. Furthermore, they actively encourage their sub-contractors to adopt the system too. "It was a bit challenging in the beginning to get everyone to use the system. But the more we use it, the more I think everyone will be properly informed that RIB Capture is the method used on the construction site." (Site manager\#3). 
C. N. Rolfsen, A. K. Lassen, M. Mohamed, A. Shakari, H. Yosefi/ Proceedings of the Creative Construction Conference (2019) 122 https://doi.org/10.3311/CCC2019-122

\section{Discussion}

Technology Acceptance Model served well as an analytical tool for explaining user choice of technology in the context of construction projects. Table 2 shows a brief summary of the main findings. The findings indicate that RIB Capture was viewed as advantageous for various aspects of the building process.

\begin{tabular}{ll} 
Table 2. Summary of results (left column) in relation to TAM items [16] (right column) \\
\hline Perceived usefulness & Perceived usefulness \\
\hline Does the job quicker & Work more quickly \\
Increased productivity and efficiency & Job performance \\
Improves flow of communication & Increase productivity and efficiency \\
Makes job easier & Makes job easier \\
\hline Perceived ease-of-use & Perceived ease-of-use \\
\hline Easy to learn & Easy to learn, clear and understandable \\
Impact of experience / age difference & Easy to become skillful \\
Easy to use & Easy to use \\
\hline Intention to use \& Actual use & \\
\hline Recommending for future projects & \\
Encouraging sub-contractors to join & \\
\hline
\end{tabular}

Faults and defects are a major problem in building projects; the main focus is on reducing the number of faults and defects during pre-inspections and handover. The case study and the results of the interviews presented show that using IT systems leads to great benefits and significant time savings on construction sites. The interviewees' views on using various software depend on whether the users see the potential and usefulness of digital tools. In the study, it was found that the users were willing to change their work methods, although they were skeptical at first.

In the group interview with the foremen of the carpenters and the plumbers in the case project, the interviewees explained that when they used the traditional method, they had to print out the forms for registration. Here, the way the registration was structured meant that the registrations collided between the different disciplines' activities, which made it difficult for the skilled workers to get a clear overview of their own activities. RIB Capture solved this problem, since registrations were sent directly to the appropriate recipient. When using RIB Capture to register faults and defects on the part of a subcontractor, this subcontractor will receive a simple message by email stating that a case has been opened on the enterprise. This was one of the positive aspects of the program that made the skilled workers prefer RIB Capture over the traditional method. Good collaboration between all the parties involved is a prerequisite for using the technology. This also means having a good flow of communication so that certain problems can be prevented before growing more serious.

Several players in the construction industry are loyal to traditional methods. This is often because site managers and skilled workers prefer to do the job they are used to doing, and because they have a conservative way of thinking that can cause frustration in relation to new work methods. The case project did not have this problem, since all the employees were between 30 and 50 years old and positive to the program. The program does not require high IT competence and is easy to use for everyone in the industry. The persons responsible for registering faults and defects felt this was more systematic in the program, and the access to information meant that the parties could easily learn the system. The skilled workers grew more interested in using the technology.

\section{Conclusion}

This paper has presented a case study of a construction project where a construction defect management app was used. By basing the study on core concepts of the Technology Acceptance Model, it became possible to answer the research question: Will digital quality management systems be accepted by the parties involved on a construction site? Our findings illustrate that 
the application was perceived as a useful tool to efficiently improve and minimize faults and defects in the completion phase of a building project. It was found that all involved parties saw the app as user-friendly, since it was easy to use and quick to master.

To gain full advantage of a digital defect management tool, it is important that everyone involved make full use of the application. In the survey, it was found that RIB Capture is likely to be adopted for use, and thereby has great potential for improving the end quality of construction projects.

\section{References}

[1] American Society for Quality. Quality Glossary, Retrieved from https://asq.org/quality-resources/quality-glossary/q 28.03.2019

[2] P. Josephson, Y. Hammarlund (1999). The causes and costs of defects in construction: A study of seven building projects, Automation in Construction, 8(6), 681-687. https://doi.org/10.1016/S0926-5805(98)00114-9

[3] K. Yue, D. Huber, B. Akinci, R. Krishnamurti (2006). The ASDMC Project: The Challenge of Detecting Defects on Construction sites, Third International Symposium on 3D Data Processing, Visualization, and Transmission. Retrieved from https://ieeexplore.ieee.org/abstract/document/4155837 28.03.2019

[4] N. Vaxevanidis, G. Petropoulos (2008). A literature survey of cost of Quality models, Journal of Engineering.

[5] R. Miettinen, S. Paavola (2014). Beyond the BIM utopia: Approaches to the development and implementation of building information modelling, Automation in Construction, 43, 84-91. https://doi.org/10.1016/j.autcon.2014.03.009

[6] S. Azhar, A. Jackson, A. Sattineni (2015). Construction Apps: A Critical Review and Analysis. ISARC Proceedings of the Conference: 32nd International Symposium on Automation and Robotics in Construction. https://doi.org/10.22260/ISARC2015/0008

[7] S. Bowden, A. Dorr, T. Thorpe, C. Anumba (2006). Mobile ICT support for construction process improvement, Automation in Construction, 15(5), 664-676. https://doi.org/10.1016/j.autcon.2005.08.004

[8] Oliver (1991). Strategic responses to institutional processes, Acadamy of Management Review 16(1) 145-179. https://doi.org/10.2307/258610

[9] F. D. Davis (1985). A technology acceptance model for empirically testing new end-user information systems: Theory and results, Sloan School of Management, MIT.

[10] E. M. Rogers (2010). Diffusion of Innovations. New York: Simon and Schuster.

[11] RIB, RIB Capture - Digital snagging, inspections, safety rounds and QA, RIB website. Retrieved from: https://www.rib-software.co.uk/ribcapture 29.03.2019

[12] C. Merschbrock (2012). Unorchestrated symphony: The case of inter - organizational collaboration in digital construction design. Journal of Information Technology in Construction, 17(22), 320-337.

[13] R. Davies., and C. Harty (2013). Implementing 'Site BIM': a case study of ICT innovation on a large hospital project, Automation in Construction, 30, 15-24. https://doi.org/10.1016/j.autcon.2012.11.024

[14] G. Lowry (2002). Modelling user acceptance of building management systems, Automation in Construction, 11(6), 695-705. https://doi.org/10.1016/S0926-5805(02)00010-9 https://doi.org/10.2307/30036540

[15] V. Venkatesh, M. G. Morris, G. B. Davis and F. D. Davis (2003). User acceptance of information technology: Toward a unified view, Management Information Systems Quarterly, 27(3), 425-478.

[16] F. D. Davis (1989). Perceived usefulness, perceived ease of use, and user acceptance of information technology, Management Information Systems Quarterly, 13(3), 319-340. https://doi.org/10.2307/249008

[17] V. Venkatesh and F. D. Davis (2000). A Theoretical Extension of the Technology Acceptance Model: Four Longitudinal Field Studies, Management Science, 46(2), 186-204. https://doi.org/10.1287/mnsc.46.2.186.11926

[18] F. D. Davis, R. P. Bagozzi and P. R. Warshaw (1989). User acceptance of computer technology: a comparison of two theoretical models, Management Science, 35(8), 982-1003. https://doi.org/10.1287/mnsc.35.8.982

[19] C. Rolfsen, C. Merschbrock (2016). Acceptance of construction scheduling visualizations: bar-charts, flowline charts, or perhaps BIM, Proceedings of the $5^{\text {th }}$ Creative Construction Conference (CCC 2016), Budapest, Hungary 2016. https://doi.org/10.1016/j.proeng.2016.11.658

[20] I. Benbasat, D.K. Goldstein, M. Mead (1987). The Case Research Strategy in Studies of Information Systems. Management Information Systems Quarterly, 11(3), 369-386. https://doi.org/10.2307/248684 